RUNNING HEAD: FLAVOUR PAIRING: A CRITICAL REVIEW OF THE LITERATURE

Food and beverage flavour pairing:

\title{
A critical review of the literature
}

\author{
Professor Charles Spence,
}

Crossmodal Research Laboratory, Oxford University

WORD COUNT: 12,800 WORDS

RESUBMITTED TO: Food Research International

DATE: FEBRUARY, 2020

CORRESPONDENCE TO: Prof. Charles Spence, Department of Experimental Psychology, Anna Watts Building, University of Oxford, Oxford, OX2 6GG, UK. E-mail: charles.spence@psy.ox.ac.uk 


\begin{abstract}
The recent explosion of interest in the topic of flavour pairing has been driven, at least in part, by the now-discredited food-pairing hypothesis, along with the emergence of the new field of computational gastronomy. Many chefs, sommeliers, mixologists, and drinks brands, not to mention a few food brands, have become increasingly interested in moving the discussions that they have with their consumers beyond the traditional focus solely on food and wine pairings. Here, two key approaches to pairing that might help to explain/justify those food and beverage combinations that the consumer is likely to appreciate are outlined. Historically-speaking, many conventional pairings emerged naturally from cultural/geographical matches, presumably internalized as semantic knowledge amongst consumers. In this review, such conventional pairings are framed as but one example of a cognitive/intellectual food-beverage strategy. The alternative approach to pairing that has become increasingly popular in recent years involves experts/commentators making recommendations based on the perceptual relationship, or interaction, between the component stimuli, be it one of perceived similarity, contrast, harmony, emergence, or modulation (either suppression or enhancement). Physicochemical accounts of pairing, based on the presence of shared flavour molecules (e.g., aromatic volatiles) in the to-be-combined flavours or ingredients, have also gained in popularity. Here, though, the latter approach is framed as an ultimately unsuccessful attempt to predict matches based on perceived similarity. This review summarizes the available evidence concerning food-beverage pairing and proposes a new dichotomy between intellectual/cognitive and perceptual pairing principles in the case of food-beverage matching.
\end{abstract}

KEYWORDS: FLAVOUR PAIRING; SIMILARITY; CONTRAST; HARMONY; EMERGENCE; MODULATION; COMPLEXITY; FOOD-PAIRING HYPOTHESIS. 


\section{Introduction}

The last few years have seen a rapid growth of interest in the pairing of foods/flavours amongst academics (e.g., Harrington \& Hammond, 2006; Harrington \& Seo, 2015; Lahne, 2018), the popular press (Anon, 2006a, b; Sample, 2006; Steinberger, 2006; Styles, 2006), and the general public alike. What started-off, in the West at least, with food and wine pairings (e.g., at highend restaurants) has recently been extended to the pairing of all manner of foods and drinks, from beer with Indian food all the way through to tea with chocolate (e.g., Donadini \& Fumi, 2014). Many chefs (e.g., Blumenthal, 2008), sommeliers (e.g., Chartier, 2012), mixologists (see Beaumont, 2006), and food and beverage (F\&B) brands (e.g., http://www.abdraught.com/ab/FoodPairings; Bellamy, 2005; Harrington, 2005; Sorilla, 2017; https://www.finecheese.co.uk/crackers-and-accompaniments/crackers-and-biscuits-forcheese.html) have also become increasingly interested in moving the discussions that they have with their consumers beyond the traditional focus solely on food pairings with wine.

Highlighting what is possible in this space, Quilon, the innovative Michelin-starred restaurant in central London has, for a number of years now, been offering a varied beer pairing menu for the South-west Indian coastal dishes that they serve (http://www.quilon.co.uk/getattachment/Menus/Beer-Tasting-Menu.pdf). Many members of the general public would also appear to have developed something of a fascination with the idea of deliberately linking what they themselves eat and drink, or else what they choose to serve to their guests. In the popular press nowadays one often finds mention of customer-facing sensory experts being challenged to provide matches/recommendations for (e.g., beers) that will pair well with particular dishes/flavour profiles (see Passy, 2014; Pierre, 2014; see also Arellano-Covarrubias, Gómez-Corona, Varela, \& Escalona-Buendía, 2019). This review summarizes the available evidence concerning pairing and to propose a new dichotomy between intellectual/cognitive and perceptual pairing principles.

\subsection{What is so interesting/challenging about food-beverage flavour pairing?}

While undoubtedly an intriguing intellectual/sensory challenge for those involved (be they chefs, sommeliers, or other sensory experts, and/or academics), as well as a seemingly irresistible marketing opportunity for many $F \& B$ brands, there are those who suggest that foodbeverage pairing actually really isn't all that important in the grand scheme of things (Centelles, 
2014; Steinberger, 2006). Countering this view, however, others have suggested that flavour pairing may even have implications for public health (Bredie, Petersen, Hartvig, Frøst, Risbo, \& Møller, 2015; see also Van Westering, 1996). Should the latter suggestion hold any weight, then trying to get a better handle on the general principles that serve as the basis for effective flavour pairing (e.g., in the domain of food-beverage matching) obviously becomes all the more important. For example, optimizing the pairing of virgin olive oil with salad or other leafy green vegetables could be seen as important in this regard (Cerretani, Biasini, BonoliCarbognin, \& Bendini, 2007; Cichelli, Cerretani, \& Piochi, in press). It might prove useful for those trying to nudge the consumer toward eating a more balanced and healthy diet by making healthy food pairings more sensorially desirable (see Spence, in press). Similarly, Cornwell and McAlister's (2013) observation that children in the US believe that soft drinks constitute a more appropriate match for French fries than steamed vegetables, whereas the reverse pairing is judged more appropriate when it comes to the better match for water, would seem relevant (if worrying) here too.

Important or not, there are those out there who do not see anything particularly complicated about developing effective flavour pairing recommendations (Maresca, 1994). There is certainly no shortage of commentators/experts confidently listing what they consider to be especially good pairings of flavours (e.g., Beckett, 2002; Chartier, 2012; Cooper, 1980; Dornenburg \& Page, 1996; Goldstein, 2006, 2010; Harrington, 2008; Immer, 2002; JohnsonBell, 1999; 'Le Cordon Bleu Matching Wine with Food', 2010; MacNeil, 2006; Segnit 2010; Walton \& Glover, 1998, p. 21; Werlin, 2003, esp. pp. 24-34). It is, however, worth noting that the underlying principles guiding such recommendations are not always entirely clear (Eschevins, Giboreau, Julien, \& Dacremont, in press; Harrington, McCarthy, \& Gozzi, 2010). Is it simply a matter of acquired experience (i.e., the result of years of trial-and-error, stored as autobiographical memories, Eschevins et al., in press)? Are some of their food-beverage pairing predictions based on the underlying similarity, and if so, of what kind (i.e., perceptual or physicochemical)? Or are those with an expert palate somehow able to predict, or detect, successful food-beverage pairings more effectively than the 'non-expert'? Of course, should the latter turn out to be a relevant consideration, one might be minded to wonder whether we can be so sure that what the expert considers a good match will necessarily be perceived or, better said, appreciated as such by the regular consumer. The latter presumably lacks the relevant domain-specific knowledge, experience, or expertise (Bastian, Payne, Perrenoud, Joscelyne, \& Johnson, 2009; Donadini, Pastori, Spigno, \& Fumi, 2008; Donadini, Spigno, 
Fumi, \& Pastori, 2008; Martinez, Hammond, Harrington, \& Wiersma-Mosley, 2017; Pettigrew \& Charters, 2006).

There is potentially also a cultural aspect to pairing too: Who knows, for instance, whether the food and beverage pairings that work so well for the western palate will necessarily succeed for those who are more accustomed to Asian cuisine (see Kim \& Lecat, 2017; Lee, 2009, 2011). Such concerns become all the more pronounced as the flavour pairing and food-bridging principles embedded in the cuisines of different cultures have been shown to differ so markedly, at least according to the latest computational gastronomy research (e.g., Ahnert, 2013; Simas, Ficek, Diaz-Guilera, Obrador, \& Rodriguez, 2017). ${ }^{1}$

Much of the academic research that has been published on flavour pairing over the last couple of decades has tended to focus on a relatively restricted range of paradigm cases, with the pairing of cheese and wine seemingly having attracted what some might see as more than its fair share of attention (e.g., see Bastian, Collins, \& Johnson, 2010; Bastian et al., 2009; Beckett, 2006; Bromberger \& Percival, 2007; Galmarini, Dufau, Loiseau, Visalli, \& Schlich, 2018; Harrington \& Hammond, 2005; Harrington et al., 2010; Visalli, 2016). One increasingly finds researchers investigating ever more unusual, or esoteric, combinations of food and beverage, such as, for example, pairing chocolates or cheese with tea, coffee, or even beer (see Donadini \& Fumi, 2014; Donadini, Fumi, \& Lambri, 2012, 2013; Donadini, Fumi, \& Newby-Clark, 2015; Friedrick, 2006). Others, by contrast, have chosen to investigate much more mundane food and beverage combinations. As a case in point, there are those who have been studying the sensory, hedonic, and emotional consequences of pairing beer and wine with pizza (Buodo, Rumiati, Lotto, \& Sarlo, 2019; Harrington, Miszczac, \& Ottenbacher, 2008; see also Donadini et al., 2008; Harrington \& Seo, 2015; Tuorila, Hyvönen, \& Vainio, 1994).

\subsection{Combinations of discrete flavour elements that do not count as flavour pairing}

At the outset, it is important to distinguish the situation when pairing food and drink from the many other occasions where one encounters discrete foods/ingredients/elements that have been

\footnotetext{
${ }^{1}$ For those who are unfamiliar, the field of computational gastronomy involves the use of big data analysis and other computational techniques to search for patterns in the way that ingredients, or flavour molecules, are combined in recipes. This data-driven approach to the analysis of recipes and flavour combination has become increasingly popular over the last decade or so, and has been facilitated by the large amounts of relevant information now available online.
} 
deliberately combined in a given tasting experience. When people talk about flavour pairing, they would mostly implicitly seem to have in mind those situations in which: 1) the discrete elements that are being paired retain their individual identity (thus ruling out blending, Wang \& Spence, 2019) and, at the same time, that: 2) each component - i.e., both the food and the drink are individually desirable as stand alone flavour experiences (thus ruling out tastemodifying agents such as miracle fruit, or fusion foods, see Spence 2018a); and furthermore that: 3 ) the taster's attention has been drawn explicitly to the nature of the relationship between the component parts of the experience. Practically-speaking, one other implicit aspect of the majority of food-drink matches is that the intensity of the component flavours typically tend to be balanced (Harrington \& Seo, 2015; Paulsen, Rognså, \& Hersleth, 2015). However, such intensity matching is taken for granted and hence rarely mentioned when experts/commentators justify the matches they make. As such, it will not be discussed further here. One of the key reasons for flavour pairing is that the combination should be experienced as better, or at least appreciated more, than either of the flavours when presented individually (Møller, 2013).

\section{Pairing food and drink}

Having narrowed in a little more explicitly on the specific situation that is of interested, when talking about flavour pairing, it is now possible to consider the ways in which researchers and sensory experts have conceptualized what may explain, and/or help to predict why a particular food and beverage pairing might make a good combination, and hence be worth recommending, or drawing a taster's attention to. Below two principal approaches to the pairing of food and drink that one finds in the literature are distinguished. There is a certain degree of overlap between them, despite the fact that one is primarily based on intellectual/cognitive considerations and the other on the perceptual consequences of pairing instead (see Table 1 for a summary).

\section{INSERT TABLE 1 ABOUT HERE}

These two broad approaches to the pairing of food and drink are discussed in more detail below, and some of the problems/challenges associated with each of them are highlighted. It should be noted here that others working in this area have not necessarily come up with exactly the same categories, nor always necessarily applied exactly the same descriptive labels. So, for instance, on the basis of their recent small-scale study of French beer and wine experts, 
Eschevins et al. (in press) proposed a large number of different pairing principles that were then grouped into three broader categories, namely Perceptual, Conceptual, and Affective (along with an 'Other' category) (see Table 2). These researchers assessed the justifications given by French experts when asked to suggest food-beverage pairings and why these pairings either would, or would not, work (see also Eschevins, 2016). Ten sommeliers and 10 beer experts were invited to suggest dishes that they believed would match one red and one white wine (St. Joseph and Muscadet Sèvre et Maine, respectively), and blond and white beers (Blond Leffe and Hoegaarden, respectively). The experts' responses were analysed using discourse analysis. Generally-speaking, the same pairing principles were used to match the food with wine as with the beer (thus speaking to the domain-generality of the pairing principles identified). However, norm-based and conceptual associations were more often mentioned in the case of food matches for wine (than for beer). While such evidence-based pairing is undoubtedly useful, the large number of pairing principles makes Eschevins et al.'s approach a little unwieldly. One might also wonder about the more theoretical underpinnings of this approach.

\section{INSERT TABLE 2 ABOUT HERE}

\section{Cognitive/Intellectual approaches to food-beverage pairing}

Before people really became interested in pairing as a phenomenon of interest in its own right, the way in which food and drinks would end up being regularly experienced together, and hence associated, would presumably have been through mere convention/convenience/availability. That is, foods and drinks originating from a particular part of the world and available at a particular time of year (think seasonality) would presumably have been experienced together, in part, because there may well have been little else to eat or drink. Over time, such constraints presumably gave rise to the emergence of distinct food cultures (Kittler \& Sucher, 2008). Varshney, Varshney, Varshney, Wang, and Myers (2013b) applied the big data computational gastronomy approach to medieval cookery books in order to try and get a sense of the flavours pairings that would have been present at the time. Indeed, relevant here, Rozin (1983) has already highlighted that particular combinations of ingredients appear to typify the foods from different regions/parts of the world. 


\subsection{Geographical pairing}

A particular form of cognitive/intellectual pairing involves matching those products that come from the same geographical region, think crudely of pairing paella with Rioja (i.e., both products from Spain), beer with sauerkraut (both originally from Alsace; Eschevins et al., in press), or Bromberger and Percival's (2007) much more geographically specific suggestion of Sancerre wine with Crotin de Chavignol cheese, since both are products of the same French commune. Eschevins et al. (in press) give the examples of Muscadet Sèvre et Maine with oysters, or Belgian beer with Flemish carbonade. Others, meanwhile, perhaps misleadingly, talk of "Terroir" pairings (see Pierre, 2014). Bear in mind here that terroir refers not only to the geographical origin of a particular product but also refers to some specific traditional practices involved in the creation of a product (a wine, say). As such, the latter might not really have any meaning for the paired products (though see Lecat \& Chapuis, 2017).

\subsection{Traditional pairing}

While certain food-beverage pairings have been established due to tradition, the notion of deliberately choosing to pair food and drink would seem to be a relatively recent invention. It is interesting to consider when and where the concept of food-beverage pairing was first introduced, and when the recent surge in popularity started. According to Eschevins et al. (in press), pairing food and beverages, primarily wine, is a traditional practice of French gastronomy. They write that: "food-wine pairing is part of the French Gastronomic Meal, registered since 2010 in the Intangible Cultural Heritage of Unesco” It would seem reasonable to suggest that whenever it began, it is an activity that is more amenable to service à la russe than to service à la française, the former introduced in France during the $19^{\text {th }}$ century. That is, pairing makes little sense when the diner is offered a range of different food options at once. This is certainly part of the problem for those looking to pair drinks with Korean cuisine. The main course and all of the side dishes tend to be presented to the diner at the same time (Kim \& Lecat, 2017). Bromberger and Percival (2007) have raised much the same challenge when it comes to recommending a wine to pair with a cheese plate/board.

It is worth remembering that the very possibility of combining foods and drinks that may have originated from different parts of the world is a luxury reserved for the contemporary globalized food market (Lee, 2009). It relies on a rich food landscape with easy access to a 
wide range of food and drink products. While those from a particular culture will presumably have internalized the pairings that are conventional within their own culture (as a form of stored semantic knowledge), they may well not be as attuned to the pairings found in the cuisines of other cultures, especially if they happen to be exotic, and thus unfamiliar to them (e.g., Seo \& Lee, 2009). Today, in high-end dining with drinks pairing menus and with expert recommendations, cultural (what some call 'geographical', see Eschevins et al., in press) approaches to pairing continue to motivate particular combinations of food and drink (e.g., Bromberger \& Percival, 2007; Eschevins et al., in press).

\subsection{Conventional vs. contrasting cognitive pairings.}

At the same time, however, it is also interesting to note how there would seem to have been an increasing tendency to move beyond simple conventional matches on tasting menus with paired drinks list, and instead to introduce drinks from a very different cultural background - such as sake with cheese (see Bromberger \& Percival, 2007), Shōchū (Japan), soju (Korea), and/or kombucha paired drinks on a modern French/British-style tasting menu. This challenging of convention can give rise to the surprise mentioned by some of the experts in Eschevins et al.'s (in press) study.

Conventional pairings may belie an underpinning perceptual alignment, such as when the style of wine-making in a particular region, is adjusted to match the foods that were typically served/eaten by those living there. At the same time however, the contrary position has also been put forward by Lecat and Chapuis (2017). The latter researchers arguing that the gastronomy and wine of Burgundy actually developed independently of one another. Without being able to rule out such perceptual origins, it is thus hard to demonstrate that cultural matches are ever purely conventional (arbitrary). It is, in other words, difficult to rule out the possibility of any element of perceptual matching. Nevertheless, when presented as a deliberate food-beverage pairing nowadays, the reasoning tends to be based on cultural match/convention, rather than any underpinning perceptual relation between the component stimuli. As such, any special appreciation of the match lies squarely on the cognitive (semantic) level in the mind of the taster. In a way, then, cultural matches can presumably be thought of as a special case of intellectual/cognitive pairing. 
To illustrate the difficulty, one might consider the rationale behind serving trout with watercress in the UK, and presumably also elsewhere (see Spence, Wang, \& Youssef, 2017). The reason, or so it has been suggested, is that the banks of the chalk streams (when and) where fishing for river trout took place would likely have been flush with watercress, as it likes much the same conditions as the fish. At first blush, this match does not seem in any sense based on a perceptual affinity between the flavours found in trout and watercress from a flavour, or flavour pairing, perspective. Rather, it would merely appear to be a match of convenience/availability that has becomes conventional, and hence increasingly familiar to those within the relevant food culture (Gerrie, 2010). One does, however, find the following in Segnit's (2010) Flavor Thesaurus: “This led Blumenthal to research the harmoniousness of pairings with ... chocolate is like a heightened version of Alain Senderens' pairing of lobster and vanilla. ... or horseradish with mackerel, cucumber with salmon, and watercress with trout." Notice the implication here that the pairing of watercress with trout may, in fact, also be explained at the perceptual level too.

Pulling apart the various explanations as to why a given pairing is a good one can, in other words, sometimes be challenging. Perhaps the best way to think about cultural matches is that common geographical origin for the food and beverage products is a necessary pre-condition for cultural pairing but it is by no means a sufficient one. After all, as Bromberger and Percival (2007, p. 139) note: “Gorgonzola renders its local Nebbiolo, Barbera, and Dolcetto-based partners metallic and bitter." The likelihood, therefore, is that cultural/conventional matches will only be chosen these days if they happen to pair well at the perceptual level. As such, one might actually consider culturally-inspired food-drink pairing to represent a subset of all possible perceptual pairings.

\subsection{Processing fluency and flavour pairing}

It is also worth bearing in mind that the repeated co-exposure to a particular combination of ingredients/flavours (such as, for example, watercress and trout) presumably makes the combination easier to process. Researchers working with the higher spatial senses, refer to the positively-valenced notion of 'processing fluency' (e.g., Winkielman, Schwarz, Fazendeiro, \& Reber, 2003; Winkielman, Ziembowicz, \& Nowak, 2015). And while the processing fluency concept has not been applied to commonly co-presented combinations of flavours (or foodbeverage combinations), there would seem little reason as to why it should not be. It would 
seem plausible that the approach could be extended to help explain why certain food-beverage pairings just seem to work, or at least work better than other pairings that are unfamiliar.

As will become important later, it is important to bear in mind that the consequences of repeated co-exposure, at least according to the processing fluency account. are primarily hedonic in nature (i.e., rather than any changes being observed at the sensory/perceptual level). In other words, the pairing may be liked more because it is processed more fluently together, but that should have no impact on the perceptual goodness of the match between the stimuli themselves. Similarly, the older literature on the 'mere exposure' effect would also predict a hedonic lift for frequently co-presented pairs of food and drink stimuli (e.g., Eschevins et al., in press; Zajonc, 1968). Consistent with this suggestion, Buodo et al. (2019) have recently reported that conventional pairings do indeed typically result in increased pleasantness. To conclude, it would seem likely that both 'processing fluency' and 'mere exposure' affect a taster's hedonic response to specific flavour pairings. This means that those who are familiar with a particular culturally- or geographically-based food-drink pairing may well find it significantly more pleasant that others who are introduced to the pairing not having experienced it previously.

\subsection{Conceptual pairing}

Other examples of conceptual pairing include the pairing of food and beverage stimuli because they are of an equivalent quality (see Eschevins et al., in press), or complexity (though see Spence \& Wang, 2018, on the complexities associated with talk of complexity as far as the chemical senses are concerned). This notion is illustrated by the comment of one the interviewees in Pettigrew and Charters' (2006) study. They suggested that, "good" wine would be wasted at a barbecue, while at a formal dinner, it would be entirely appropriate, while cask wine would fail. Alternatively, food and beverage may be paired because they share a similar process of creation (i.e., both rely on fermentation). Indeed, this can be considered just one of the possible justifications for the decision to pair wine with cheese (see Galmarini et al., 2018; King \& Cliff, 2005). Pairing cheese and wine, a common combination in the literature, is not automatically a cognitive/intellectual match unless the taster's attention happens to be drawn to this feature when the pair is introduced. It is possible to consider food-beverage pairing that is based on shared flavour molecules as constituting yet another example of conceptual pairing. According to the conceptual pairing approaches outlined by Eschevins et al. (in press) (see 
Table 1), additional suggestions include matches based on 'Norms' (by which they mean classic pairings), the 'Moment of the meal', 'Specific situation', and 'Season'.

One challenge here is to know whether attributes such as quality/complexity can be perceived directly, in which case they might be considered a perceptual match based on similarity. However, as Spence and Wang (2018) have suggested, it can be argued that complexity is inferred rather than directly perceived. As such, it would seem more appropriate to place this approach here amongst the cognitive/intellectual pairing accounts. Ultimately, the ease of processing that is bred by familiarity leads to a likely increase in processing fluency. In a sense, this is a perceptual outcome, but more on the affective/hedonic side rather than the sensorydiscriminative side that is the focus of the perceptual approaches to pairing.

\section{Perceptual approaches to food-beverage pairing}

The second main approach to food-beverage pairing is based on the perceptual relation between the food and beverage stimuli. This approach is based primarily on the perceptual, rather than cognitive/intellectual consequences of pairing food and drink. The justification for this kind of food and drink pairing seems to reside entirely within the taster's perceptual experience. Intriguingly, a number of different possible desirable, and not so desirable, perceptual outcomes have been outlined in the literature, and were frequently mentioned by the French sensory experts quizzed by Eschevins et al. (in press; see Table 2). The perceptual outcomes of pairing that these researchers talk about include: Similarity, contrast, harmony, emergence, and modulation (be it either enhancement or suppression). Each of these perceptual outcomes of pairing food and drink will now be examined in detail.

\subsection{Perceptual similarity}

Similarity-based pairings involve the selection of two products (one food and one beverage, in this case) because they share one or more perceptual properties (see Eschevins et al., in press). The food and drink may be paired because they have a similar aroma, flavour, taste, texture, or perhaps even just because they have a similar colour (i.e., visual appearance). To illustrate the perceptual similarity-based matching approach, just take the first four of the following winecheese pairing recommendations from Werlin (2003): “(1) pairing light white wines with light 
cheeses (such as goat's or sheep's milk cheeses with a Chenin Blanc), (2) pairing high-acid white wines with high-acid cheeses (such as an aged chèvre with a cool-climate Sauvignon Blanc), (3) pairing low-acid wines with lower-acid cheeses (such as a gouda with a California Chardonnay), (4) pairing strong wines with strong cheeses (such as aged cheddar and Syrah or Rhone reds), and (5) pairing dessert wines with strong, salty cheeses (such as blue-veined cheeses and Sauternes or Port)" (quote taken from Harrington et al., 2010, p. 312). Similaritybased matching is a safer bet that many of the other perceptual pairing techniques, or principles, that one might use, according to many of the experts quizzed by Eschevins et al. (in press). Food-beverage pairings based on aromatic similarity have been reported to lead to increased harmony (Eschevins, Giboreau, Allard, \& Dacremont, 2018). Similarity would also seem to be at work with Bromberger and Percival's (2007, p. 144) suggestion of pairing full-bodied high umami sake with washed-rind cheeses and some Cheddar cheeses, since both are high in the umami-taste.

\subsection{Perceptual contrast}

This is sometimes referred to as balance, as when those in the world of fine wine talk of the well-balanced contrast between sweetness and acidity. Bromberger and Percival (2007, p. 142) illustrate the notion of contrast-based perceptual pairings when suggesting that: "The high salt content of blue cheeses contrasts beautifully with intense sweetness; Roquefort and Sauternes is sublime, but so too are Stilton and Cabrales. ” Notice here, once again, the implicit matching of stimulus intensity.

\subsection{Perceptual harmony}

This is defined by Eschevins et al. (in press) as "how well sensations go together", and has often been shown to correlate with how much a particular food-beverage pairing is liked (Eschevins et al., 2018; Paulsen et al. 2015). The idea of searching for those pairings that give rise to a harmonious perceptual experience also crops-up in work on pairing olive oil with leafy greens (e.g., Cerretani et al., 2007; Cichelli et al., in press; Spinelli, 2014). According to Kim and Lecat (2017, p. 2): “'Harmony with food' is one of the top reasons Koreans drink wine." 
In the earlier quote from Segnit's (2010) book, top chef Heston Blumenthal was also interested in the harmoniousness of specific food pairings.

\subsection{Perceptual emergence}

This refers to the situation in which a new perceptual element (e.g., a new taste, aroma, flavour, texture, or mouth-feel) that is not present in either of the component parts is created when specific food and beverage items are paired. In the setting of the laboratory, it has been reported that certain combinations of odorants can occasionally give rise to the perception of a different odour quality. In this case, though, the component odours are no longer identifiable (Mitchell \& McBride, 1971). Of course, the emergence of a new perceptual element might either constitute a reason to pair, or else not to pair, food and drink. A number of the sommeliers in Eschevins et al.'s (in press) study talked about the possibility of "new characteristics" emerging when pairing wine with food. However, that said, the latter were mostly concerned with the potential risk of creating "off-flavours". As a case in point, it has long been observed that when artichoke (Cynara scolymus) is eaten together with a drink of water (Bartoshuk, Lee, \& Scarpellino, 1972; Blakeslees, 1935; Woods, 1971), or wine (Beard, 1971; Brody, 1972; Centelles, 2014; Graves, 1967), the latter often tastes much sweeter as a result.

In this case, a substance in the artichokes (cynarin) latches on to the sweet-taste receptors without actually activating them. Nothing happens until a person takes a drink, at which point the cynarin molecules are washed away, releasing the receptors, and triggering a perception of sweetness in roughly $60 \%$ of those tested. This physical interaction clearly has perceptual consequences (namely, the emergence of a sweet taste) that is not obviously present in either the drink (e.g., the water) or the artichoke (the food). Hence, this well-documented pairing (to avoid), should be categorized as a negative example of emergence. Specifically, the emergent sweet taste upsets the fine balance between sweetness and acidity that many people look for in a fine (i.e., balanced) wine. Some experts, like sommelier Ferran Centelles, have though been exploring whether there might not be combinations of wine and artichoke, depending on the preparation of the latter, that do manage to combine well together (Centelles, 2014). Should Centelles be successful in his quest, the resulting pairings need not necessarily involve emergence. 
The traditional recommendation to avoid pairing red wine with seafood / white fish (e.g., Simon, 1996, pp. 10-19), constitutes another negatively-valenced example of perceptual emergence. Of course, as with any rule, there are always those who want to challenge the convention, showing that red wine can be the friend of fish and poultry, while certain white wines can pair well with red meat (see Harrington, 2008; Harrington \& Seo, 2015; Rosengarten \& Wesson, 1989). Once again, this well-known example of the negative consequences of pairing has a physical, rather than perceptual, origin. Research by Tamura, Taniguchi, Suzuki, Okubo, Takata, and Konno (2009) has shown that it is the iron-chelating properties of the winefish pairing that lead to the negative perceptual consequence, often reported as a ferrous or bitter taste, and an unpleasant fishy and/or metallic odour. Contemporary wine-making practices do, though, seem to have alleviated this problem somewhat, by eliminating the ferrous ion from the majority of red wines (e.g., see Youssef et al., 2017).

To the extent that the latter two suggestions of food-drink pairings to avoid are based on the emergence of an undesirable perceptual element in the combined tasting experience, these examples clearly fit into the perceptual-level account. What is more, in both cases, the causes of this perceptual emergence are physical interactions, whose underlying mechanisms are now reasonably well understood. In this sense, these two examples also feel somehow importantly different from the other perceptual-level examples of pairing that have been discussed so far in this section (namely similarity, contrast, and harmony). In the latter three cases, the interaction was considered to be occurring solely (or primarily) within the taster's perceptual experience (i.e., there was no physical account to explain what was going on).

It is no coincidence that both of the examples reported so far in this section constitute reasons not to pair food and drink: Negative examples of emergence just seem to be more common than positive ones in the literature on food-beverage pairing. Though perhaps one might include the following suggestion from Bromberger and Percival (2007, p. 142) in the latter category: "a young, fresh, high-moisture goat's cheese is a marvelous match for a jammy late-picked California Zinfandel - a pairing reminiscent of dolloping jam on a slice of cheesecake." The emergent property in this case appears to have a purely perceptual, rather than physical, explanation. Other examples of purely perceptual emergence have been documented in the world of flavour perception (Spence, 2016), and a few isolated examples have also been documented amongst the higher spatial senses as well (see Spence, 2015a, for a review). 


\subsection{Perceptual modulation}

Perceptual modulation can be observed either as an enhancement or as a suppression of a particular sensory property of the food or drink. Once again, modulation may constitute a reason to pair food and drink, or not to do so. It all depends on whether the element in the tasting experience that is affected is itself desirable or not. The loss (or absence) of sensation often appears to be the outcome when food and drink (e.g., wine and cheese) are paired. There is also a rich literature highlighting the modulation, often involving mutual suppression, when various combinations of olfactory and gustatory stimuli are combined in a tasting experience under laboratory conditions (e.g., see Barkat, Le Berre, Coureaud, Sicard, \& Thomas-Danguin, 2012; Blumenthal, 2008, pp. 232-237; Breslin \& Beauchamp, 1997; Keast \& Breslin, 2002; Lawless, 1986; Kim, Son, Kim, Misaka, \& Rhyu, 2015; Noble, 1996; Thomas-Danguin, Sinding, Romagny, El Mountassir, Atanasova, Le Berre, Le Bon, \& Coureaud, 2014). For instance, the participants in one study by Madrigal-Galan and Heymann (2006) gave lower ratings of the perceived intensity of vegetal, mint, and mushroom aromas in red wines when paired with various cheeses. These researchers also reported that several of the cheeses blunted the perception of oak and berry flavours in the wines too. At the same time, the buttery aroma in the wine was enhanced by the consumption of cheese.

Similarly, a few years earlier, Nygren, Gustafsson, and Johansson (2003) had already reported that drinking wine tended to decrease the buttery flavour, saltiness and sourness of subsequently-tasted blue cheeses. Elsewhere, Donaldini et al. (2013) noted that eating Parmesan cheese led to a decrease in the subsequent perception of bitterness, astringency, malty flavour, carbonation and alcohol level in beer. Across the literature, many such negative (or suppressive) food-beverage interactions have been reported. It is this that is part of what makes achieving successful food-beverage pairing such a challenge (contrary to the suggestions of certain commentators in the literature; see Maresca, 1994).

One positive suppressive effect documented in Madrigal-Galan and Heymann's (2006) study was that cheese decreased the perceived astringency of the wine. This is presumably because proteins in the cheese bound the tannins in the wine, as well as the fact that the cheese will have coated the surface of the tasters' mouths with fat. Harsh wines, in other words, can be made to seem soft and lush in the presence of fat, as US wine expert Karen MacNeil has noted. At the same time, it is worth noting that astringent drinks, such as tannic wine and some teas, can help reduce the perception of fattiness in food (e.g., Mura, Yagi, Kizaki, Matsumiya, 
Matsumura, \& Hayashi, 2017; Peyrot des Gachons, Mura, Speziale, Favreau, Dubreuil, \& Breslin, 2012). Some of the experts quizzed by Eschevins et al. (in press) made much the same point when suggesting that the aim behind certain food-beverage pairings might be to help mask a negative, or disliked characteristic in the other product. As one sommelier put it, when justifying a particular combination: "(the Blond Leffe beer) will bring a refreshing side, it will somewhat mitigate the violence of anchovies or certain olives".

While the absence (or suppression) of sensation may indeed be an undesirable consequence of pairing red wine with cheese, there are other situations in which it is considered desirable. This the underpinning physical logic behind the oft-mentioned suggestion that red meat (e.g., steak) should be paired with a tannic red wine. In this case, it is the proteins in the red meat that will help to break-down the tannins which will be coagulated by the proteins on the tongue, thus lowering the astringent mouthfeel that is normally associated with drinking such wine. See, for example, Garcia-Estevez, Ramos-Pineda, and Escribano-Bailon (2018), on the science underpinning the interactions between wine phenolic compounds and human saliva in the perception of astringency.

\subsection{Interim summary}

In summary, therefore, there are several perceptual outcomes that one might be looking to elicit, or else to avoid, when pairing food and drink, summarized here under the following headings: similarity, contrast, harmony, emergence, and modulation (either enhancement or suppression). More of the present review is given over to the perceptual pairing account than to the intellectual/cognitive account. In part, this reflects the literature more generally, with far more research having been published that deals with perceptual-type pairing. While conventional pairing may be far more common in our everyday food experiences, there is perhaps less of academic interest to merit researchers working in this area. While the outcomes of these particular pairing principles are always experienced perceptually, that does not necessarily mean that the explanation for these outcomes also resides solely in the taster's perceptual experience. As has been discussed in a number of cases, researchers have been able to uncover physicochemical interactions giving rise to such perceptual effects. This leads on to a specific explanation for why the pairing of food and drink might work at a perceptual level. However, before moving on to the physicochemical approach to perceptual similarity-based 
food-beverage pairing, it is worth pointing out that regular co-exposure to flavourful stimuli not only potentially changes the taster's hedonic response to them, but can also change their perceptual properties (and associations) as well.

\section{Prior co-exposure based influences on the goodness of similarity-based perceptual pairing}

Earlier, when discussing the cultural account of pairing, it was noted that regular co-exposure to flavourful stimuli, as in a particular combination of food and drink, might result in an increased liking for the match due to the 'mere exposure effect' (Zajonc, 1968), and/or the associated increase in 'processing fluency' (Winkielman et al., 2003, 2015). Such hedonic effects should presumably not have any direct effect on the goodness of a pairing at the perceptual level. At the same time, however, regular co-exposure to gustatory and olfactory stimuli can also change the perceptual qualities of the latter, hence raising the possibility that some aspects of perceptual similarity may, in fact, be learned (e.g., Breslin, Belanger, Tharp, \& Dalton, 2003). Certain aromas have been shown to take on the taste quality with which they are typically associated in food and drink (Blank \& Mattes, 1990; Stevenson \& Boakes, 2004). This acquired increase in perceptual similarity appears to be something that emerges only for pairings of olfactory and gustatory stimuli (i.e., it does not occur when auditory and visual stimuli are paired, for example), and would seem to be unidirectional. A number of researchers have noted that aromas, especially novel ones, become more perceptually similar to the gustatory taste quality with which they are paired, such as, for example, in the case of vanilla aroma taking on sweet qualities after repeated co-exposure with the aroma in sweet foods. There is, though, little discussion of similar effects having been observed in the other direction. There may be good grounds for the asymmetrical nature of this relationship. In particular, it has been suggested that this particular perceptual change may help the taster to localize relevant food source out there in the environment (Lim, Fujimaru, \& Linscott, 2014; Linscott \& Lim, 2016).

What such an asymmetrical crossmodal effect presumably means, in practice, is that the perceived similarity of food and beverage combinations might not be a fixed property of the stimuli themselves, but may instead vary as a function of a taster's prior tasting history (specifically, their co-exposure to the relevant stimuli; cf. Haller, Rummel, Henneberg, Pollmer, \& Köster, 1999; Sakai, Kobayakawa, Gotow, Saito, \& Imada, 2001). As such, it may 
not always be possible to guarantee that a particular food-beverage pairing that happens to be perceived as similar by one taster will necessarily be experienced in the same way by another person. This touches on the whole issue of individual differences in taste/flavour perception (see below for further discussion). This should also be considered in relation to Eschevins et al.'s (in press) category of 'Individual preferences' (see Table 2).

\section{Managing complexity when pairing food and beverage}

When considering food-beverage pairing it is important to bear in mind that there is a sense of an optimal level of complexity as far as flavour experiences are concerned. Any combination of food and drink must presumably be more complex that the more complex of the component elements in the pair (though see Wang \& Spence, 2019). Hence those in charge of orchestrating tasting experiences need to make sure that food-beverage pairing where each of the components are themselves complex does not lead to a combination that is too overwhelming for the taster to appreciate, as should that point be reached, the hedonic response is likely to be reduced (see Lévy, MacRae, \& Köster, 2006; Spence, 2018b).

\section{The physicochemical approach to pairing and the food-pairing hypothesis}

\subsection{The food-pairing hypothesis}

At this point, it is interesting to consider the physicochemical basis of similarity-based perceptual matches. While traditionally such matching was considered solely at the level of psychology/perception, there has been growing interest in trying to predict perceptual similarity/matching on the basis of physicochemical similarity of the component stimuli. This approach is neutral with regard to where the chemical constituents that are being paired arise, i.e., in ingredients within a dish, or the food-beverage pairing that we are primarily interested in in this review. One specific version of this kind of approach, originally proposed by François Benzi and Heston Blumenthal, is popularly referred to as the food-pairing hypothesis (Blumenthal, 2008; see Ahn \& Ahnert, 2013; Ahnert, 2011, 2013). Much of the recent interest from chemists and computational gastronomists in the topic of flavour perception has been focused on trying to explain/predict good flavour pairings (and/or any patterns in the cooccurrence of ingredients in recipes) on the basis of the chemical similarity between the 
component flavour molecules (Ahn \& Ahnert, 2013; Ahn, Ahnert, Bagrow, \& Barabási, 2011; Ahnert, 2013; Jain, Rakhi, \& Baglerb, 2015a, b). A website associated with this approach has been developed by Bernard Lahousse (Lahousse, 2019; see https://www.foodpairing.com/; https://www.foodpairing.com/en/home).

Many of those working in the emerging field of computational gastronomy have built on the fundamental idea underpinning the food-pairing hypothesis, namely that: "If two ingredients share important flavour compounds, then they will go well together." (Ahn \& Ahnert, 2013, p. 272). De Klepper (2011, p. 55) provides a slightly more nuanced definition, namely that: "The more aromatic compounds two foods have in common, the better they taste together. This effect is particularly strong when two foods share aromas that make up their characteristic flavour." For instance, Chef Watson from IBM makes suggestions for ingredients to combine on the basis of an algorithm that uses traditional pairings, regional pairings, flavour profiles, aroma (flavour) pairing, and learnt pairings from recipes developed by chefs who have used the system. That said, anecdotal reports in the press suggest that Chef Watson's unusual pairings of flavours and eclectic mixing of culinary styles are actually not always appealing (e.g., Trout, 2015; see also Taft, 2014; Wakefield, 2014).

A number of attention-capturing unusual flavour combinations that initially seemed to support the food-pairing hypothesis included the combinations of white chocolate and caviar, chocolate and blue cheese, and pork liver and jasmine (see Blumenthal, 2002, 2008, pp. 171-172; de Klepper, 2011). White chocolate and caviar both contain amines, while pork liver and jasmine share the volatile compound indole. Other popular food combinations that share volatile compounds include salmon and liquorice, bananas and parsley, oysters and passion fruit, and garlic, coffee, and chocolate (the latter trio sharing the volatile compound 2-methylfuran-3thiol, de Klepper, 2011). While it is certainly true that much of the literature on food pairing has tended to focus on combining unusual ingredients in food or drink recipes, there is no reason why the approach should not be extended to the pairing of food and drink. Indeed, this would seem to have been precisely the approach taken by Frederic Chartier (2012). While Chartier's book is itself short on detail as to how the recommended pairings were developed (was the process more art than science, one wonders?), the recent collaboration between the sommelier and Sony, as presented at the 2019 Science and Cooking World Congress held in Barcelona (Chartier \& Kitano, 2019), would certainly seem to suggest a move toward a more scientific computational gastronomy approach. 
Chartier (2012, p. 211) describes what he does as molecular sommelerie, establishing foodwine pairings at the molecular level, defining it as: "the practice of developing food pairings based on dominant aromatic compounds". Notice here how the perceptual consequences of adopting the food-pairing hypothesis would seem to be restricted to predicting similarity-based perceptual matches. It is unclear whether anyone has tried to predict perceptual contrast, harmony, emergence, or modulation on the basis of shared chemical composition of a particular food and beverage combination.

\subsection{Evaluating the food-pairing hypothesis}

Problematically though, formal assessment of the predictive validity of the food-pairing hypothesis has failed to support it (e.g., Bredie et al., 2015; Kort, Nijssen, van Ingen-Visscher, \& Donders, 2010; Traynor, Burke, O'Sullivan, Hannon, \& Barry-Ryan, 2013). For instance, Kort et al. describe in a conference proceedings paper putting the hypothesis to the test with a group of untrained participants. de Klepper (2011, p. 58) describe the results as follows: "food pairings with more aroma overlap did not taste better than food pairings with less overlap. For example, chocolate and tomato (43\% overlap) did not taste better than cauliflower and pear (no overlap)." de Klepper (2011, p. 56) concludes that: "food pairing based on aromatic overlap is not a guaranteed recipe for success. Balancing flavors is what does the trick." (see also Blumental, 2010).

The fundamental problem for the food-pairing hypothesis, as well as for any other attempt to predict the perceptual response to a particular combination of flavour molecules based on their structure/composition, is that there is simply no one-to-one mapping between molecular structure and the associated flavour experience. This, contrary to the claim one sometimes finds in the literature (e.g., see Jain et al., 2015a, p. 3, for one particularly clear suggestion along just these lines; see Kruger, Feldzamen, \& Miles, 1955). See Spence et al. (2017), for various reasons as to why this is not the case (see also Blumenthal, 2008, pp. 171-172).

At this point, one might ask whether there is something of a contradiction between the failure of the food-pairing account and the computational gastronomy approach promoted by Ahnert and colleagues. The explicit aim of the food-pairing account is to predict successful new combinations of flavours/ingredients, whereas computational gastronomy is primarily concerned with analysing the statistical relationship between flavour compounds in existing 
recipes, typically those that have been documented on the internet. As such, while both approaches are interested in the chemical composition of foodstuffs/ingredients they are trying to do quite different things. It is not incongruent to argue against the food-pairing hypothesis while at the same time supporting the computational gastronomy approach.

In summary, therefore, the fundamental problem with the computational approach to flavour pairing, searching as it does for ingredients that share common chemical constituents, is that it simply doesn't work as a general pairing principle (de Klepper, 2011). This despite the continued popularity of companies such as Flavour Pairing (see https://www.foodpairing.com/; https://www.foodpairing.com/en/home), whose poster was for a long time to be found on the walls of many a top restaurant kitchen. Use of the food-pairing hypothesis neither guarantees, nor does it necessarily predict (at a level that is significantly above chance), good food-beverage combinations. One of the main problem with this approach to flavour pairing, at least as it was originally formulated, is that it is based solely on shared compounds, without taking perceptual thresholds into consideration (though see Varshney, Pinel, Varshney, Bhattachrjya, Schörgendorfer, \& Chee, 2013a;, for an exception). Of course, just because the food-pairing hypothesis, and the subsequent computational gastronomy approach, cannot guarantee good food-beverage pairings, that does not mean that physicochemical accounts of pairing have no place. At one level, shared flavour molecules might nevertheless still provide grounds for conceptually matching food and drink (as mentioned earlier). Separately, it is clear that the food-pairing hypothesis also provides a means of generating novel combinations of ingredients (de Klepper, 2011), while the computational gastronomy approach has highlighted the existence of robust differences in the degree of overlap of flavour molecules in the ingredients of recipes from different cultures.

\subsection{Pairing based on physical characteristics}

Cheese expert Bronwen Bromberger and her husband, wine expert Frances Percival, have argued for an approach to wine-cheese with that is based on the physical properties/characteristics of the component stimuli (Bromberger \& Percival, 2007). They point out that batch variation in the majority of quality (i.e. farmhouse) cheeses makes any attempt to specify precise cheese-wine pairings pointless, as what works today may well not work tomorrow when sampling a different batch of the same cheese (that may perhaps have been aged for a different length of time). One other problem relates to the variation between cheese 
and rind, i.e., very often the cheese itself should not simply be considered as a homogenous product. Instead, they argue for a more careful consideration of the chemical make-up of, and variation in, cheese. While much of the popular discourse in the case of wine-cheese matching has been around fat, and its mouth-coating properties, Bromberger and Percival suggest that this might be something of a red-herring; At least inasmuch as the fat content of cheeses do not tend to vary anything like as much as do levels of salt and acidity,. They therefore suggest focusing on the salt content, moisture content, and acidity of cheeses as the physical attributes that determine a good match with wine instead (since these vary much more between cheeses).

However, while frequently talking about the physicochemical composition of the cheeses that they discuss, it is a little unclear whether what Bromberger and Percival (2007) really have in mind in terms of driving good cheese and wine matches is not the perceived level of saltiness, rind character, acidity, and umami (which, after all, can differ quite markedly from the physical concentration of the relevant taste-associated elements; see also Koone, Harrington, Gozzi, \& McCarthy, 2014). To the extent that it is really the perceived level of salt and acidity that they have in mind, Bromberger and Percival's suggestion might seem more appropriately positioned in the perceptual similarity account of pairing, as described earlier. Much the same argument can be made concerning Eschevins et al.'s (2018) suggestion that effective cheese-wine pairings are often based on aromatic similarity. Here, once again, it is perceived rather that molecular similarity that would appear to be key to explaining the success of the match.

\section{Individual differences in perception and their implications for perceptual pairing}

One important issue that has not really been discussed thus far relates to individual differences in chemosensory perception. The perceptual account is based on a similar perceptual response to the to-be-paired stimuli, something that can by no means be guaranteed. Just take, for example, those flavour compounds where there are profound genetically-determined perceptual differences (see Reed \& Knaapila, 2010). A large percentage of the population perceive cilantro/coriander as tasting unpleasantly soapy, whereas the majority think it tastes pleasantly herby (Mauer \& El-Sohemy, 2012). It is perhaps for this reason that one might expect not to come across quite so many food-beverage pairings involving this particular ingredient. Nevertheless, given that there are relatively few foods showing such marked individual differences in perceptual quality, and to the extent that one downplays any perceptual threshold differences across the population, this should not constitute an 
insurmountable hurdle for those interested in the world of perceptually-motivated flavour pairing (Reed \& Knaapila, 2010). The well-documented individual differences in taster status are presumably also worth bearing in mind here (e.g., Bartoshuk, 2000; Garneau, Nuessle, Sloan, Santorico, Coughlin, \& Hayes, 2014). However, I am not aware of anyone having mentioned this factor as it pertains to flavour pairing thus far. This is perhaps because it is the olfactory contribution that is such a key part of the experience of tasting (see Spence, 2015b, for a review).

\section{Conclusions}

There has been an explosive growth of interest in flavour pairing in recent years. Chefs, brands, the popular press, consumers, computer scientists, and sensory scientists alike have all seemingly become increasingly interested in trying to understand/predict good food and drink combinations. However, while the literature is full of recommendations for good matches to try, as well as a few bad combinations that may best be avoided, oftentimes the basis on which such recommendations are made is unclear. In this literature review, two broad approaches to the pairing of food and drink are outlined: These are the cognitive/intellectual and perceptual approaches. One of the suggestions to emerge from this review is that cultural matches can be considered a subset of cognitive/intellectual matches, though as was also highlighted, they are likely to be chosen only if the result of the combination is perceptually pleasing (see Bromberger \& Percival, 2007).

Given the mismatch that is often observed between flavour chemistry and perceptual experience, the physicochemical account of pairing, as embodied in the flavour pairing hypothesis likely only operates successfully when framed in terms of a conceptual match operating at the cognitive/intellectual level. That said, it is interesting to note how certain of the perceptual approaches to pairing have a physicochemical explanation, while others seem to require an explanation solely within the taster's perceptual experience, possibly modulated by their prior experience to specific combinations of taste and flavour.

While some have questioned the importance of flavour pairing, there are others who believe it to represent not just a great marketing opportunity for F\&B brands, chefs, sommeliers, and mixologists, but that it may also have broader implications for public health; Some commentators can even see a role in the context of promoting gastrotourism (see Bredie et al., 
2015; Harrington, 2005; Van Westering, 1996). Beyond the food-drink pairing that has formed the subject matter of this review, one might, also want to consider the extent to which similar pairing principles can be applied to the emerging field of sonic seasoning, when e.g., food and drink are matched to specific pieces of music, or soundscapes (see Spence, 2017; Spence, Reinoso-Carvalho, Velasco, \& Wang, 2019; Spence \& Wang, 2015a, b, c). Broadening one’s scope even further, one might also want to consider the pairing of grape varieties with glass shapes (see Spence, 2011), or the pairing of cheese with biscuits. There are, in other words, many different kinds of pairing that are of interest to those working in the world of food and drink. As is always the case, therefore, there are plenty more intriguing questions to be addressed in the terms of the pairing of food and drink, and, in this case, a largely receptive audience wanting to know the answers while putting the pairing principles into practice.

In conclusion, the main contribution of this review is to suggest that all of the food-beverage pairing principles that have been put forward over the years can simply be distilled down to just two: one approach based on cognitive/intellectual food-beverage matching, and the other based on the perceptual consequences of pairing. The practical implications of this are that this simplification should hopefully help those interested in presenting flavour pairing to their customers to deal sensibly with what can, at times, seem like a bewilderingly complex area. 


\section{REFERENCES}

Ahn, Y.-Y., \& Ahnert, S. E. (2013). The flavor network. Leonardo, 46, 272-273.

Ahn, Y.-Y., Ahnert, S. E., Bagrow, J. P., \& Barabási, A.-L. (2011). Flavor network and the principles of food pairing. Scientific Reports, 1:196, 1-6.

Ahnert, S. E. (2013). Network analysis and data mining in food science: The emergence of computational gastronomy. Flavour, 2:4.

Anon. (2006a). Vintage or vile, wine is all the same after cheese. New Scientist, 2535, 16. https://www.newscientist.com/article/mg18925354-700-vintage-or-vile-wine-is-all-the-sameafter-cheese/.

Anon. (2006b). Wine and cheese 'not best match'. BBC News Online, January $19^{\text {th }}$. http://news.bbc.co.uk/1/hi/health/4625324.stm.

Arellano-Covarrubias, A., Gómez-Corona, C., Varela, P., \& Escalona-Buendía, H. B. (2019). Connecting flavors in social media: A cross cultural study with beer pairing. Food Research International, 115, 303-310.

Barkat, S., Le Berre, E., Coureaud, G., Sicard, G., \& Thomas-Danguin, T. (2012). Perceptual blending in odor mixtures depends on the nature of odorants and human olfactory expertise. Chemical Senses, 37, 159-166.

Bartoshuk, L. M. (2000). Comparing sensory experiences across individuals: Recent psychophysical advances illuminate genetic variation in taste perception. Chemical Senses, 25, 447-460.

Bartoshuk, L. M., Lee, C. H., \& Scarpellino, R. (1972). Sweet taste of water induced by artichoke (Cynara scolymus). Science, 178, 988-990.

Bastian, S. E. P., Collins, C., \& Johnson, T. E. (2010). Understanding consumer preferences for Shiraz wine and Cheddar cheese pairings. Food Quality and Preference, 21(7), 668-678. http://dx.doi.org/10.1016/j.foodqual.2010.02.002.

Bastian, S. E. P., Payne, C. M., Perrenoud, B., Joscelyne, V. L., \& Johnson, T. E. (2009). Comparisons between Australian consumers' and industry experts' perceptions of ideal wine and cheese combinations. Australian Journal of Grape and Wine Research, 15(2), 175-184. http://dx.doi.org/10.1111/j.1755-0238.2008.00043.x.

Beard, J. (1971). Gourmet, 31, 30.

Beaumont, S. (2006). Cocktailians \& restaurateurs raise the bar with beer \& food pairings. Nation's Restaurant News, 40(37), 1-3.

Beckett, F. (2002). How to match food and wine. London, UK: Mitchell Beazley.

Beckett, F. (2006). So what wine does go with cheese? Decanter, December, 30-33.

Bellamy, G. (2005). Beer-food pairings brew up interest. Restaurant Hospitality Journal, 89(7), 98.

Blakeslees, A. F. (1935). A dinner demonstration of threshold differences in taste and smell. Science, 81, 504-507. 
Blank, D. M., \& Mattes, R. D. (1990). Sugar and spice: Similarities and sensory attributes. Nursing Research, 39, 290-293.

Blumenthal, H. (2002). Weird but wonderful. The Guardian, May $4^{\text {th }}, 84$. https://www.theguardian.com/lifeandstyle/2002/may/04/foodanddrink.shopping.

Blumenthal H. (2008). The big Fat Duck cookbook. London, UK: Bloomsbury.

Blumenthal, H. (2010). Naivety in the kitchen can lead to great inventions, but too much can take you to some strange places. The Times, August 19 ${ }^{\text {th }}, 45$.

Bredie, W. L. P., Petersen, M. A., Hartvig, D., Frøst, M. B., Risbo, J., \& Møller, P. (2015). Flavour pairing of foods: A physical-chemical and multisensory challenge for health promotion. European Sensory Network. http://www.esn-network.com/index.php?id=1034.

Breslin, P. A. S., \& Beauchamp, G. K. (1997). Salt enhances flavor by suppressing bitterness. Nature, 387, 563.

Breslin, P. A. S., Belanger, M. A., Tharp, C. D., \& Dalton, P. (2003). Learned flavor congruency: The importance of experience in the sub-threshold integration of tastant/odorant pairings. Paper presented at the $5^{\text {th }}$ Pangborn Symposium, Boston, USA.

Brody, J. E. (1972). Artichoke's taste effects confirmed by a scientist. The New York Times, December $\quad 3^{\text {rd }}$. https://www.nytimes.com/1972/12/03/archives/artichokes-taste-effectsconfirmed-by-a-scientist.html.

Bromberger, B., \& Percival, F. (2007). Culture shock: Principles for successful wine-andcheese pairing. The World of Fine Wine, 16, 138-145.

Buodo, G., Rumiati, R., Lotto, L., \& Sarlo, M. (2019). Does food-drink pairings affect appetitive processing of food cues with different rewarding properties? Evidence from subjective, behavioral, and neural measures. Food Quality \& Preference, 75, 124-132.

Centelles, F. (2014). Can wine and artichokes ever be friends? May $4^{\text {th }}$. Downloaded from www.jancisrobinson.com.

Cerretani, L., Biasini, G., Bonoli-Carbognin, M., \& Bendini, A. (2007). Harmony of virgin olive oil and food pairing: A methodological proposal. Journal of Sensory Studies, 22, 403416.

Chartier, F. (2012). Taste buds and molecules: The art and science of food, wine, and flavor (translated by Levi Reiss). Hoboken, NJ: John Wiley and Sons.

Chartier, F., \& Kitano, H. (2019). The aromatic theory of molecular harmonies and sommelery. Paper presented at the Science \& Cooking World Congress, Barcelona, February 4- $6^{\text {th }}$.

Cichelli, A. Cerretani, L., \& Piochi, M. (in press). Bitter taste in vegetables vs bitter taste and green flavour in extra virgin olive oil: Harmony of oil and food pairing. International Journal of Gastronomy \& Food Science.

Cooper, D. (1980). Wine with food. London, UK: Octopus Publishing.

Cornwell, T. B., \& McAlister, A. R. (2013). Contingent choice. Exploring the relationship between sweetened beverages and vegetable consumption. Appetite, 62, 203-208.

De Klepper, M. (2011). Food pairing theory: A European fad. Gastronomica: The Journal of Food and Culture, 11, 55-58. 
Donadini, G., \& Fumi, M. D. (2014). An investigation on the appropriateness of chocolate to match tea and coffee. Food Research International, 63, 464-476. http://dx.doi.org/10.1016/j.foodres.2014.05.038.

Donadini, G., Fumi, M. D., \& Lambri, M. (2012). The hedonic response to chocolate and beverage pairing: A preliminary study. Food Research International, 48(2), 703-711. http://dx.doi.org/10.1016/j.foodres.2012.06.009.

Donadini, G., Fumi, M. D., \& Lambri, M. (2013). A preliminary study investigating consumer preference for cheese and beer pairings. Food Quality and Preference, 30(2), 217-228. http://dx.doi.org/10.1016/j.foodqual.2013.05.012.

Donadini, G., Fumi, M. D., \& Newby-Clark, I. R. (2015). An investigation of matches of bottom fermented red beers with cheeses. Food Research International, 67, 376-389. http://dx.doi.org/10.1016/j.foodres.2014.11.004.

Donadini, G., Pastori, R., Spigno, G., \& Fumi, M. D. (2008). Beer and food pairing: Agreement and disagreement between experts and regular consumers. Does theory match the practice? In 30th Asia Pacific Section-Convention 2008-The Institute of Brewing \& Distilling (pp. 1-31). Institute of Brewing and Distilling

Donadini, G., Spigno, G., Fumi, M. D., \& Pastori, R. (2008). Evaluation of ideal everyday Italian food and beer pairings with regular consumers and food and beverage experts. Journal of the Institute of Brewing, 114(4), 329-342. http://dx.doi.org/10.1002/j.20500416.2008.tb00777.x.

Dornenburg, A., \& Page, K. (2006). What to drink with what you eat: The definitive guide to pairing food with wine, beer, spirits, coffee, tea - even water - Based on expert advice from America's best sommeliers. USA: Little, Brown, \& Company.

Eschevins, A. (2016). From beverage to companion food: Experts' principles for pairing wines and beers with food. Paper presented at Eurosense 2016, 11-14 ${ }^{\text {th }}$ September, Dijon, France.

Eschevins, A., Giboreau, A., Allard, T., \& Dacremont, C. (2018). The role of aromatic similarity in food and beverage pairing. Food Quality \& Preference, 65, 18-27.

Eschevins, A., Giboreau, A., Julien, P., \& Dacremont, C. (in press). From expert knowledge and sensory science to a general model of food and beverage pairing with wine and beer. International Journal of Gastronomy \& Food Science.

Friedrick, J. (2006). Get ideas brewing for cheese \& beer pairings. Gourmet News Periodical, June, 12-13.

Galmarini, M. V., Dufau, L., Loiseau, A.-L., Visalli, M., \& Schlich, P. (2018). Wine and cheese: Two products or one association? A new method for assessing wine-cheese pairing, Beverages, 4:13. DOI:10.3390/beverages4010013.

Garcia-Estevez, I., Ramos-Pineda, A. M., \& Escribano-Bailon, M. T. (2018). Interactions between wine phenolic compounds and human saliva in astringency perception. Food \& Function, 9, 1294-1309. http://dx.doi.org/10.1039/c7fo02030a.

Garneau, N. L., Nuessle, T. M., Sloan, M. M., Santorico, S. A., Coughlin, B. C., \& Hayes, J. E. (2014). Crowdsourcing taste research: Genetic and phenotypic predictors of bitter taste perception as a model. Frontiers of Integrative Neuroscience, 8:33. doi:10.3389/fnint.2014. 00033 
Gerrie, A. (2010). Watercress: Best of the bunch. The Independent, May $\mathbf{5}^{\text {th }}$. https://www.independent.co.uk/life-style/food-and-drink/features/watercress-best-of-thebunch-1962378.html.

Goldstein, E. (2006). Perfect pairings - A master sommelier's practical advice for partnering wine and food. Oakland, CA: University of California Press.

Goldstein, E. (2010). Daring pairings - A master sommelier matches distinctive wines with recipes from his favorite chefs. Oakland, CA: University of California Press.

Graves, E. (1967). Life, 62, 114.

Haller, R., Rummel, C., Henneberg, S., Pollmer, U., \& Köster, E. (1999). The influence of early experience with vanillin in food preference later in life. Chemical Senses, 24, 465-467.

Harrington, R. J. (2006). The wine and food pairing process: Using culinary and sensory perspectives. Journal of Culinary Science \& Technology, 4(1), 101-112.

Harrington, R. J. (2008). Food \& wine pairing. A sensory experience. Hoboken, NJ: John Wiley \& Sons.

Harrington, R. J., \& Hammond, R. (2005). The direct effects of wine and cheese characteristics on perceived match. Journal of Foodservice Business Research, 8(4), 37-54.

Harrington, R. J., \& Hammond, R. (2006). Body deviation-from-match: The yin and yang of wine and food pairing? Journal of Culinary Science \& Technology, 5(1), 51-69.

Harrington, R. J., \& Hammond, R. (2009). The impact of wine effervescence levels on perceived palatability with salty and bitter foods. Journal of Foodservice Business Research, 12, 234-246.

Harrington, R. J., McCarthy, M., \& Gozzi, M. (2010). Perceived match of wine and cheese and the impact of additional food elements: A preliminary study. Journal of Foodservice and Business Research, 13(4), 311-330.

Harrington, R. J., Miszczac, D. C., \& Ottenbacher, M. C. (2008). The impact of beer type, pizza spiciness and gender on match perceptions. PASOS. Journal of Tourism and Cultural Heritage, 6(2), 173-188.

Harrington, R. J., \& Seo, H. S. (2015). The impact of liking of wine and food items on perceptions of wine-food pairing. Journal of Food Service Business Research, 18, 489-501.

Immer, A. (2002). Great tastes made simple: Extraordinary food and wine pairing for every palate. New York, NY: Broadway Books.

Jain, A., Rakhi, N. K., \& Baglerb, G. (2015). Spices form the basis of food pairing in Indian cuisine. http://arxiv.org/ftp/arxiv/papers/1502/1502.03815.pdf.

Jain, A., Rakhi, N. K., \& Bagler, G. (2015). Analysis of food pairing in regional cuisines of India. PLoS ONE, 10:e0139539. doi:10.1371/journal.pone.0139539.

Johnson-Bell, L. (1999). Good food, fine wine: The essential guide to matching food and wine. London, UK: Cassell PLC.

Keast, R. S. J., \& Breslin, P. A. S. (2002). An overview of binary taste-taste interactions. Food Quality and Preference, 14, 111-124.

Kim, M. J., Son, H. J., Kim, Y., Misaka, T., \& Rhyu, M.-R. (2015). Umami-bitter interactions: The suppression of bitterness by umami peptides via human bitter taste receptor. Biochemical 
and Biophysical Research Communications, 456(2), 586-590. http://doi.org/10.1016/j.bbrc.2014.11.114.

Kim, S., \& Lecat, B. (2017). An exploratory study to develop Korean food and wine pairing criteria. Foods, 3:40. doi:10.3390/beverages3030040.

King, M., \& Cliff, M. (2005). Evaluation of ideal wine and cheese pairs using a deviationfrom-ideal scale with food and wine experts. Journal of Food Quality, 28(3), 245-256. http://doi.org/10.1111/j.1745-4557.2005.00033.x.

Kittler, P. G., \& Sucher, K. P. (2008). Food and culture (5 ${ }^{\text {th }}$ Ed.). California: Thomson Wadsworth.

Koone, R., Harrington, R. J., Gozzi, M., \& McCarthy, M. (2014). The role of acidity, sweetness, tannin and consumer knowledge on wine and food match perceptions. Journal of Wine Research, 25(3), 158-174.

Kort, M., Nijssen, B., van Ingen-Visscher, K., \& Donders, J. (2010). Food pairing from the perspective of the 'volatile compounds in food' database. In I. Blank, M. Wüst, \& C. Yeretzian (Eds.), Expression of multidisciplinary flavour science: Proceedings of the 12th Weurman Symposium, Interlaken, Switzerland (pp. 589-592). Winterthur: Institut of Chemistry and Biological Chemistry.

Kruger, L., Feldzamen, A. N., \& Miles, W. R. (1955). A scale for measuring supra-threshold olfactory intensity. The American Journal of Psychology, 68, 117-123.

Lahne, J. (2018). Evaluation of meals and food pairing. In G. Ares \& P. V. Tomasco (Eds.), Methods in consumer research (Vol. 2, pp. 85-107). Duxford, UK: Woodhead.

Lahousse, B. (2019). Food pairing. The digitization of food. Paper presented at the Science \& Cooking World Congress, Barcelona, February 4- $6^{\text {th }}$.

Lawless, H. T. (1986). Sensory interaction in mixtures. Journal of Sensory Studies, 1, 259-274.

Lecat, B., \& Chapuis, C. (2017). Food and wine pairing in Burgundy: The case of Grands Crus. Beverages, 3:10.

'Le Cordon Bleu Matching Wine with Food' (2010). London, UK: Carroll \& Brown Publishers.

Lee, J. C. (2009). Asian palate-Savouring Asian cuisine \& wine. Hong Kong: Asset Publishing and Research Limited.

Lee, J. C. (2011). Mastering wine for the Asian palate. Hong Kong: Asset Publishing and Research Limited.

Lee, K. (2009). Is a glass of Merlot the symbol of globalization? An examination of the impacts of globalization on wine consumption in Asia. International Journal of Wine Business Research, 21, 258-266.

Lévy, C. M., MacRae, A., \& Köster, E. P. (2006). Perceived stimulus complexity and food preference development. Acta Psychologica, 123(3), 394-413. DOI:10.1016/j.actpsy.2006.06.006.

Lim, J., Fujimaru, T., \& Linscott, T. D. (2014). The role of congruency in taste-odor interactions. Food Quality \& Preference, 34, 5-13.

Linscott, T. D., \& Lim, J. (2016). Retronasal odor enhancement by salty and umami tastes. Food Quality \& Preference, 48, 1-10. 
MacNeil, K. (2006). Wine, food \& friends. Des Moines, IA: Oxmoor House.

Madrigal-Galan, B., \& Heymann, H. (2006). Sensory effects of consuming cheese prior to evaluating red wine flavour. American Journal of Enology \& Viticulture, 57, 12-22.

Maresca, T. (1994). The right wine. New York, NY: Grove Atlantic.

Martinez, D. C., Hammond, R., Harrington, R. J., \& Wiersma-Mosley, J. D. (2017). Young adults' and industry experts' subjective and objective knowledge of beer and food pairings. Journal of Culinary Science \& Technology, 15, 285-305.

Mauer, L., \& El-Sohemy, A. (2012). Prevalence of cilantro (Coriandrum sativum) disliking among different ethnocultural groups. Flavour, 1:8.

Mitchell, M. J., \& McBride, R. L. (1971). Effects of propanol masking odor on the olfactory intensity scaling of eugenol. Journal of Experimental Psychology, 87, 309-313.

Møller, P. (2013). Gastrophysics in the brain and body. Flavour, 2(8), 2-4.

Mura, E., Yagi, M., Kizaki, Y., Matsumiya, K., Matsumura, Y., \& Hayashi, Y. (2017). Analysis of active components on oral fat sensations in Oolong tea. Food Science and Technology Research, 23(1), 71-78. http://doi.org/10.3136/fstr.23.71.

Noble, A. C. (1996). Taste-aroma interactions. Trends in Food Science \& Technology, 7(12), 439-444. http://doi.org/10.1016/S0924-2244(96)10044-3.

Nygren, I. T., Gustafsson, I. B., \& Johansson, L. (2003). Perceived flavour change in blue mould cheese after tasting white wine. Food Service Technology, 3, 143-150.

Passy, C. (2012). As craft brew sales grow frothy, pourers with pedigrees bubble up. The Wall Street Journal, November $\quad \mathbf{1 3}^{\text {th }}$. https://www.wsj.com/articles/SB10001424052970204349404578101094006848474.

Paulsen, M. T., Rognså, G. H., \& Hersleth, M. (2015). Consumer perception of food-beverage pairings: The influence of unity in variety and balance. International Journal of Gastronomy and Food Science, 2(2), 83-92. http://dx.doi.org/10.1016/j.ijgfs.2014.12.003.

Pettigrew, S., \& Charters, S. (2006). Consumers' expectations of food and alcohol pairing. British Food Journal, 108(3), 169-180. http://doi.org/10.1108/00070700610650990.

Peyrot des Gachons, C., Mura, E., Speziale, C., Favreau, C. J., Dubreuil, G. F., \& Breslin, P. A. S. (2012). Opponency of astringent and fat sensations. Current Biology, 22(19), R829-R830.

Pierre, E. (2014). Le guide Hachette des bières [The Hachette guide to beer]. New York, NY: Hachette.

Reed, D. R., \& Knaapila, A. (2010). Genetics of taste and smell: Poisons and pleasures. Progress in Molecular Biology Translational Science, 94, 213-240.

Rosengarten, D., \& Wesson, J. (1989). Red wine with fish: The new art of matching wine with food. New York, NY: Simon \& Schuster.

Rozin, E. (1983). Ethnic cuisine: The flavor-principle cookbook. Brattleboro, VT: The Stephen Greene Press.

Sakai, N., Kobayakawa, T., Gotow, N., Saito, S., \& Imada, S. (2001). Enhancement of sweetness ratings of aspartame by a vanilla odor presented either by orthonasal or retronasal routes. Perceptual and Motor Skills, 92, 1002-1008.

Sample, I. (2006). Use ropey old plonk to accompany cheese. The Guardian, January $\mathbf{1 9}^{\text {th }}$. https://www.theguardian.com/science/2006/jan/19/food.research. 
Segnit, N. (2010). The flavour thesaurus: Pairings, recipes and ideas for the creative cook. London, UK: Bloomsbury.

Seo, S., \& Lee, J. E. (2009). Consumers perception of Korean foods compatible with traditional Korean liquors. Korean Journal of Food Culture, 24, 1-9.

Simas, T., Ficek, M., Diaz-Guilera, A., Obrador, P., \& Rodriguez, P. R. (2017). Food-bridging: A new network construction to unveil the principles of cooking. Frontiers in ICT, 4:14. doi: 10.3389/fict.2017.00014

Simon, J. (1996). Rules, \& how to break them. In D. Cooper (Ed.), Wine with food. London, UK: Octopus Publishing.

Sorilla IV, G. (2017). Unveiling Martell's fine spirits through food pairings. Philippine Tatler, December $1^{\text {th }}$. https://ph.asiatatler.com/dining/unveiling-martell-s-fine-spirits-through-foodpairings.

Spence, C. (2011). Crystal clear or gobbletigook? The World of Fine Wine, 33, 96-101.

Spence, C. (2015a). Cross-modal perceptual organization. In J. Wagemans (Ed.), The Oxford handbook of perceptual organization (pp. 649-664). Oxford, UK: Oxford University Press.

Spence, C. (2015b). Just how much of what we taste derives from the sense of smell? Flavour, 4:30.

Spence, C. (2016). Oral referral: On the mislocalization of odours to the mouth. Food Quality \& Preference, 50, 117-128.

Spence, C. (2017). Sonic seasoning. In L. Minsky \& C. Fahey (Eds.), Audio branding: Using sound to build your brand (pp. 52-58). London, UK: Kogan Page.

Spence, C. (2018a). Contemporary fusion foods: How are they to be defined, and when do they succeed/fail? International Journal of Gastronomy \& Food Science, 13, 101-107.

Spence, C. (2018b). Complexity on the menu and in the meal. Foods, 7:158.

Spence, C. (in press). Gastrophysics: Nudging consumers toward eating more leafy (salad) greens. Food Quality \& Preference. https://doi.org/10.1016/j.foodqual.2019.103800.

Spence, C., Reinoso-Carvalho, F., Velasco, C., \& Wang, Q. J. (Eds.). (2019). Auditory contributions to food perception and consumer behaviour. Leiden, NL: Brill.

Spence, C., \& Wang, Q. (J.). (2015a). Wine \& music (I): On the crossmodal matching of wine \& music. Flavour, 4:34.

Spence, C., \& Wang, Q. (J.). (2015b). Wine \& music (II): Can you taste the music? Modulating the experience of wine through music and sound. Flavour, 4:33.

Spence, C., \& Wang, Q. (J.). (2015c). Wine \& music (III): So what if music influences taste? Flavour, 4:36.

Spence, C., \& Wang, Q. J. (2018). On the meaning(s) of complexity in the chemical senses. Chemical Senses, 43, 451-461.

Spence, C., Wang, (Q.) J., \& Youssef, J. (2017). Pairing flavours and the temporal order of tasting. Flavour, 6:4. DOI 10.1186/s13411-017-0053-0; http://rdcu.be/pStQ.

Spinelli, S. (2014). Investigating the culinary use of olive oils. In E. Monteleone \& S. Langstaff (Eds.), Olive oil sensory science (pp. 195-225). Chichester, UK: Wiley Blackwell. 
Steinberger, M. (2006). Say cheese! Turns out it goes fine with red wine. Slate, February $17^{\text {th }}$. http://www.slate.com/id/2136470/?nav=tap3.

Stevenson, R. J., \& Boakes, R. A. (2004). Sweet and sour smells: Learned synaesthesia between the senses of taste and smell. In G. A. Calvert, C. Spence, \& B. E. Stein (Eds.), The handbook of multisensory processing (pp. 69-83). Cambridge, MA: MIT Press.

Styles, O. (2006). Wine and cheese incompatible, says research. Decanter, January $\mathbf{1 9}^{\text {th }}$. https://www.decanter.com/wine-news/wine-and-cheese-incompatible-says-research-95439/.

Taft, D. K. (2014). Cognitive cooking: Inside IBM's Watson food truck. eWeek, March $14^{\text {th }}$. http://www.eweek.com/database/slideshows/cognitive-cooking-inside-ibms-watson-foodtruck.html.

Tamura, T., Taniguchi, K., Suzuki, Y., Okubo, T., Takata, R., \& Konno, T. (2009). Iron is an essential cause of fishy aftertaste formation in wine and seafood pairing. Journal of Agriculture \& Food Chemistry, 57, 8550-8556.

Thomas-Danguin, T., Sinding, C., Romagny, S., El Mountassir, F., Atanasova, B., Le Berre, E., Le Bon, A.-M., \& Coureaud, G. (2014). The perception of odor objects in everyday life: A review on the processing of odor mixtures. Frontiers in Psychology, 5:504. http://doi.org/10.3389/fpsyg.2014.00504.

Traynor, M. P., Burke, R., O'Sullivan, M. G., Hannon, J. A., \& Barry-Ryan, C. (2013). Sensory and chemical interactions of food pairings (basmati rice, bacon and extra virgin olive oil) with banana. Food Research International, 54, 569-577.

Trout, C. (2015). I trusted my gut to IBM's Watson and it gave me a fowl old-fashioned. Engadget, May 15 ${ }^{\text {th }}$. http://www.engadget.com/2015/05/15/drinking-with-watson/.

Tuorila, H., Hyvönen, L., \& Vainio, L. (1994). Pleasantness of cookies, juice and their combinations rated in brief taste tests and following ad libitum consumption. Journal of Sensory Studies, 9(2), 205-216. http://doi.org/10.1111/j.1745-459X.1994.tb00241.x.

Van Westering, J. M. (1996). Gastronomy, the importance of combining tastes. In J. S. A. Edwards (Ed.), Culinary arts and sciences; global and national perspectives (pp. 15-24). New York, NY: Computational Mechanics Publications.

Varshney, L. R., Pinel, F., Varshney, K. R., Bhattachrjya, D., Schörgendorfer, A., \& Chee, Y.M. (2013a). A big data approach to computational creativity. IEEE International Conference on Cognitive Informatics and Cognitive Computing (pp. 1-16). July. New York, NY.

Varshney, K. R., Varshney, L. R., Wang, J., \& Myers, D. (2013b). Flavor pairing in medieval European cuisine: A study in cooking with dirty data. Proceedings of the International Joint Conference on Artificial Intelligence Workshops, pp. 3-12.

Visalli, M. (2016). Results of the analysis of the wine-cheese data collected during the social program. Presentation Given at EuroSense 2016. Dijon, France.

Wakefield, J. (2014). What would a computer cook for dinner? BBC News Online, March $7^{\text {th }}$. http://www.bbc.co.uk/news/technology-26352743.

Walton, S., \& Glover, B. (1998). The ultimate encyclopedia of wine, beer, spirits \& liqueurs. London, UK: Lorenz Book.

Wang, Q. J., \& Spence, C. (2019). Is complexity worth paying for? Investigating the perception of wine complexity for single varietal and blended wines in consumers and experts. Australian Journal of Grape and Wine Research, 25, 243-251. 
Werlin, L. (2003). The all-American cheese and wine book: Pairings, profiles and recipes. New York, NY: Stewart, Tabori and Chang.

Winkielman, P., Schwarz, N., Fazendeiro, T., \& Reber, R. (2003). The hedonic marking of processing fluency: Implications for evaluative judgment. In J. Musch, \& K. C. Klauer (Eds.), The psychology of evaluation: Affective processes in cognition and emotion (pp. 189-217). Mahwah, NJ: Erlbaum.

Winkielman, P., Ziembowicz, M., \& Nowak, A. (2015). The coherent and fluent mind: How unified consciousness is constructed from cross-modal inputs via integrated processing experiences Frontiers in Psychology, 6:83. https://doi.org/10.3389/fpsyg.2015.00083

Woods, W. M. (1971). Artichokes. Science, 193, 1195.

Zajonc, R. B. (1968). Attitudinal effects of mere exposure. Journal of Personality and Social Psychology, 9, 1-28. 